\title{
Academic freedom as a keyword
}

\section{BOOK TITLE:}

Academic freedom in a democratic South Africa: Essays and interviews on higher education and the humanities

\section{AUTHOR: \\ John Higgins}

ISBN:

9781868147519

\section{PUBLISHER:}

Wits University Press,

Johannesburg, R290

\section{PUBLISHED:}

2013

\section{REVIEW TITLE:}

Academic freedom as a keyword

\section{REVIEWER: \\ Lis Lange}

EMAIL:

LangeML@ufs.ac.za

\section{AFFILIATION:}

Directorate for Institutional Research and Academic Planning, University of the Free State, Bloemfontein, South Africa

\section{POSTAL ADDRESS:}

Directorate for Institutional Research and Academic Planning, University of the Free State, P0 Box 339, Bloemfontein 9300 , South Africa

\section{HOW TO CITE:}

Lange L. Academic freedom as a keyword. S Afr J Sci. 2014;110(1/2), Art. \#a0051, 2 pages. http://dx.doi. org/10.1590/sajs.2014/a0051

\author{
(C) 2014. The Authors. \\ Published under a Creative \\ Commons Attribution Licence.
}

John Higgins's Academic Freedom is a worthy example of what Said refers to in the book as the fugal and contrapuntal approach to literacy (p. 219). The author's attention to the simultaneity of voices is not unlike Glen Gould playing Bach and produces a similar effect: a will to listen more and to engage further.

Academic Freedom is organised in two parts. Part One consists of five essays published by the author in different formats between 1987 and 2011. Two of them focus directly on academic freedom (Chapters 1 and 2), while the other three focus on different aspects of the position of the humanities in higher education policy and practice in the last 30 years. Part Two consists of interviews with Terry Eagleton, Edward Said and Jakes Gerwel, all of whom have directly contributed to the debate about the humanities and the role of universities and intellectuals in society. Finally, the book closes with a conclusion that, instead of summarising already stated arguments, presents the issues at stake against the current policy and political context in South Africa. A foreword by John Coetzee in the form of a letter to the author adds flair to a text that is fundamentally dialogical.

Like all good writing Higgins's Academic Freedom is susceptible to several different readings. I would like to propose four: an historical reading, a political reading, a pedagogical reading and an intellectual reading.

In the historical reading Higgins deals with academic freedom as the construction of a problem from the debates about De Klerk's Regulations of 1987 to the launch of the Charter for the Humanities (2011) and the amendments to the Higher Education Act introduced by the Minister of Higher Education and Training in 2012. The local chronology might be misleading. Far from concentrating on South African higher education, Higgins explores the changing relationship between higher education and the state and higher education and society as part of the global expansion and influence of neo-liberalism. From this perspective Higgins navigates through fundamental higher education texts contraposing and combining the detailed analysis of policy and policy reports with specialised higher education literature. The main concern here is the seemingly easy transition from a conception of higher education 'as a sub-set of the political system to a sub-set of the economic system' (p. 156) and the instrumentalist conceptualisation of higher education which arises from this. In doing this, Higgins does not stop at the door of governments, states and markets, but goes inside higher education institutions, exploring how the overriding instrumental motive manifests itself in the tensions between universities' management and academics. The continuum in this historical reading of Higgins's work is the impact that these changes have had on the humanities disciplines in terms of self-definition as well as for their position, valorisation and funding within universities. Higgins's argument is far from simplistic, antiquated or romantic. He dissects the contradictions and tensions of 21 st century higher education, particularly in the context of post-apartheid South Africa, at the same time that he makes the case for the humanities as eminently necessary disciplines for the 21 st century informatics society.

A political reading of Academic Freedom brings us back to Said's Reith Lectures (1973) on the representations of the intellectual and his/her role in 'disturbing the easy flow and circulation of received ideas' (p. 2). Higgins's minute dissection of the notion of 'occasioned' writing lays out the difficulties of a type of writing which is developed academically but that is stated for and in public. Each one of the essays comes from a combination of what the American Association of University Professors calls in its definition of academic freedom 'extramural utterances' and rigorous academic writing; thus newspaper articles and public lectures are woven through Higgins's text. The point of this writing is to take a position, which Higgins does in every chapter. The political reading of Academic Freedom is confirmed in the final counterpoint between the arguments contained in the five essays and the three interviews with academics who are also intellectuals and whose participation in public debate and political life has been exemplary. The notion that the humanities disciplines are necessary for democratic life because they educate people in the art of dissecting discourse, constructing arguments and asking questions about the questions, argued throughout the book, speaks, in my view, to the fundamental bastion of the political in higher education: the conceptualisation of education itself as a political act in an agoric sense and it serves to show in practice the social value of critical literacy.

Academic Freedom is also susceptible to a pedagogical reading. This reading is particularly true of the five essays but can also be detected in the conversation about education that takes place in all three interviews. From Chapter 1 onwards, in subsequent levels of complexity and explicitness, Higgins proposes a humanities pedagogy. He usefully argues that critical literacy is the name of the project 'standing behind or within' the common ground of all humanities disciplines (p. 83), a notion that some local academics still find difficult to grasp. From the specific pedagogical perspective, Higgins not only analyses text and discourse, he shows how to do it. In chapter after chapter, Higgins deploys the three dimensions of textuality, theory and history that constitute critical literacy as exemplars of what he means. The analysis of institutional culture as a keyword, the observations about the difference between statement and address in policy documents (and in any argument for that matter) and the introduction of the NAIL (narrative, analysis, interpretation and language) disciplines are all teaching moments, as is his minute analysis of the debates on academic freedom in Chapters 1 and 2. Inevitably, the pedagogical moment is also a political moment as Higgins insists on the importance of understanding the uneven distribution of cultural capital among university students and the possibility of looking at universities' 'institutional cultures' from the point of view of the 'pedagogic culture and its forms of transmission' (p. 127). Once again the pedagogical reading is sustained in the interviews as all three interviewees use their experience as university teachers to reflect on the difficulties of teaching critical literacy to the millennial generation.

My last reading of Higgins is intellectual in the sense of the author's intellectual perspective in the analysis of the problem at hand. The analysis presented in Academic Freedom is unambiguously and unashamedly materialistic. Higgins's own deployment of the theoretical, the historical and the textual is grounded in the material connection 
between culture and society. Raymond Williams's oeuvre, on which Higgins has worked extensively, becomes a primary frame of reference for the analysis of the humanities in the context of academic freedom. The exploration of institutional culture as a keyword (Chapter 4) is probably the best, but by no means the only, example of this. The notion of keyword as 'an item of contested vocabulary in a conflicted and disputed social process' (p. 103) sets the scene for an exploration of the manner in which words and concepts change meaning under the pressure of social and political change. Both text and footnotes rely on Marx and historical materialism as still useful lenses to interpret reality; thus we move from The German Ideology to the Critique of Hegel's Theory of the State and the Theses on Feuerbach as part of the same argument. The reader should not be misled to think that what Higgins's text offers is a simplistic Marxist analysis of a social problem. This materialist approach engages with Bourdieu, Derrida and Foucault as much as with more recent postcolonial theory. As in the other proposed readings of Academic Freedom, in the intellectual reading the five essays and the interviews operate in a fugue structure and Eagleton, Said and Gerwel, from different personal experiences, multiply the reflection on the value and need of thinking with Marx against Marx, to reappropriate a phrase coined by Benhabib apropos of Arendt. Of particular interest for South African reflection is the dialogue with Gerwel about race and class in local politics in a post-socialist world.

It is possible and necessary to argue with the author from a variety of points of view in order to explore further the implications of some of the notions and definitions proposed, to examine again the role of whiteness and given epistemologies in institutional culture, to introduce the possibility that the author's conceptualisations are very marked by his South African institutional context, and to explore further the permanent tension in the definition of the university and its role in society under different historical moments. Yet this does not detract from the quality of the argument or the importance of the book. As with all good arguments Academic Freedom is bound to induce debate and provoke the possibility of public deliberation. At a time when there is not sufficient public debate in the country as to the suitability of our interpretive schemes to understand and act in our society, Higgins's work is a good incentive to reflect on the extent to which academia can hold on to the double responsibility of interpreting the world and helping to change it, and on the political conditions under which this might be possible. 